\title{
Erosive tooth wear among South Brazilian adolescents, and its association with sociodemographic variables
}

\author{
Débora Nunes de Oliveira \\ RACKI(a) \\ Ângela DALLA NORA ${ }^{(b)}$ \\ Letícia Donato COMIM(a) \\ Julio Eduardo do Amaral \\ ZENKNER(b) \\ Luana Severo ALVES(a) \\ (a) Universidade Federal de Santa Maria - \\ UFSM, School of Dentistry, Department \\ of Restorative Dentistry, Santa Maria, \\ RS, Brazil. \\ (b) Universidade Federal de Santa Maria - \\ UFSM, School of Dentistry, Department of \\ Stomatology, Santa Maria, RS, Brazil.
}

Declaration of Interests: The authors certify that they have no commercial or associative interest that represents a conflict of interest in connection with the manuscript.

\section{Corresponding Author:}

Luana Severo Alves

E-mail: luanaseal@gmail.com

https://doi.org/10.1590/1807-3107bor-2019.vol33.0119

Submitted: June 25, 2019

Accepted for publication: October 15, 2019

Last revision: November 8, 2019

\begin{abstract}
The aim of this study was to assess the occurrence of erosive tooth wear (ETW) among 15-19-year-old South Brazilian adolescents, regarding prevalence, extent, severity, intraoral distribution, and sociodemographic risk indicators. A population-based cross-sectional survey was conducted in Santa Maria, southern Brazil, and included a representative sample of 15-19-year-old adolescents. Data collection included the application of a questionnaire and a clinical examination. A questionnaire was sent to the parents/legal guardians of the selected students, containing questions on demographic information, socioeconomic characteristics, and living conditions. After tooth cleaning and drying, all erupted permanent teeth were clinically assessed by two calibrated examiners, and classified according to the Basic Erosive Wear Examination (BEWE). The association between explanatory variables and the outcomes (ETW prevalence and extent) was assessed using Poisson regression models (both unadjusted and adjusted). A total of 1,197 adolescents were included in the study (participation rate of $72.3 \%$ ). The overall prevalence of ETW was $57 \%$. Severe ETW affected $16 \%$ of the sample. Overall, this adolescent population presented 13.3 affected surfaces, and 8.34 affected teeth. In the risk assessment analysis, gender, skin color, socioeconomic status, and family income were significantly associated with ETW. Boys, white adolescents, and those with higher socioeconomic status were more affected by ETW. This population-based cross-sectional study revealed that the prevalence of ETW was high, and that it was associated with sociodemographic variables in this South Brazilian population of adolescents.
\end{abstract}

Keywords: Tooth Erosion; Adolescent; Cross-Sectional Study; Epidemiology; Prevalence.

\section{Introduction}

Erosive tooth wear (ETW) is defined as chemical wear of the dental structure, as a result of extrinsic or intrinsic acids or chelators acting on plaque-free tooth surfaces. ${ }^{1}$ This is a multifactorial condition, since its presence and severity depend on several factors, such as nutrition, saliva, general diseases, and behavioral and lifestyle habits. ${ }^{2}$ There are several studies assessing ETW among adolescents, ${ }^{3,4,5,6,7,7,9,9,10}$ 
with prevalence rates ranging from $1.4 \%$ in India ${ }^{7}$ to $59.85 \%$ in Poland. ${ }^{3}$ In Brazil, there is only one study assessing the occurrence of ETW among 15-19-year-old adolescents, ${ }^{10}$ which is the age range advocated by the Brazilian Ministry of Health for assessing adolescents in national oral health surveys. After evaluating 675 adolescents attending urban public schools from Campina Grande, Paraíba, the authors found an ETW prevalence rate of $21 \%$. This study investigated the association between ETW and dietary factors, but no association could be established. Further studies are required on the occurrence of ETW among Brazilian adolescents.

Despite the wealth of data on the association between eating habits and ETW, ${ }^{4,5,6,8}$ little is known about the effect of sociodemographic variables on the occurrence of ETW. A study by Kirthiga et al. ${ }^{7}$ observed that Indian public school attendees had a greater prevalence of ETW than students from private schools ( $p<0.01$ ). However, the type of school was not significantly associated with ETW in the risk assessment analysis. In regard to family income, no association was found among Brazilian adolescents and young adults. ${ }^{4,10}$ Most diseases occur due to the conditions in which people are born, live, work, and grow old. ${ }^{11}$ Oral health, as an integral part of general health, is influenced by the same factors, especially the socioeconomic conditions of the population. ${ }^{12}$ ETW may also be influenced by these socioeconomic factors, ${ }^{13}$ which could explain the greater susceptibility of some individuals compared with others, ${ }_{r}^{14}$ however, this relationship has been studied only scarcely, and no major conclusion has been drawn. Better knowledge of the association between socioeconomic variables and ETW could lead to the development of preventive strategies focused on the target population.

ETW has a progressive and destructive nature, develops in a silent and asymptomatic manner, and the affected individual is commonly unaware and uninformed. In addition, its early establishment warrants an investigation of possible risk indicators in young populations. Therefore, the aim of this study was to assess the occurrence of ETW among South Brazilian adolescents aged 15 to 19 years, regarding prevalence, extent, severity, intraoral distribution, and sociodemographic risk indicators.

\section{Methodology}

\section{Study design and sample}

A cross-sectional study was carried out to assess the oral health status of 15-19-year-old adolescents from Santa Maria, a mid-sized city located in southern Brazil. Santa Maria had an estimated population of 278,445 inhabitants in 2017, and was the fifth most populated city in its state, Rio Grande do Sul. The municipality has been supplied with fluoridated water for more than 30 years. In 2011, caries prevalence was $39.3 \%$, and the mean DMFT (decayed, missing, filled teeth) was 0.9 at 12 years. ${ }^{15}$ All the 37 high schools in the municipality were invited to participate in the study (26 public and 11 private). Adolescents born in the years 2003, 2002, 2001, 2000 and 1999, attending any school period (morning, afternoon, or night), were considered eligible for the study. A simple random sampling procedure was adopted in each school. Subjects were randomly selected proportional to school size, using a table of random numbers. Individuals using fixed orthodontic appliances, or those presenting special needs were excluded from the sample.

Considering a prevalence rate of $50 \%$ (worst case scenario), a 95\% confidence interval (CI), a power of $80 \%$, and a precision level of $3 \%$, it was estimated that 1,066 students would be required for the present study. A non-participation rate of $50 \%$ was factored in, totaling 1,600 adolescents to be invited to participate.

\section{Data collection}

Data collection was conducted from March to November 2018, and included the application of a questionnaire and clinical examination. A questionnaire was sent to the parents/legal guardians of the selected students, containing questions on demographic information (gender, age, and skin color), socioeconomic characteristics (mother's and father's education, socioeconomic status, and family income), and living conditions (household crowding, tap water, and paved streets). The questionnaire was previously tested and adjusted to allow better comprehension.

The clinical examination was performed in a room provided by the school, with the students in a supine position, after tooth cleaning with a 
toothbrush and toothpaste, isolation with cotton rolls, and surface drying, under artificial light, using a probe and clinical mirror. All erupted permanent teeth were assessed and classified according to the Basic Erosive Wear Examination (BEWE) ${ }^{16}$, except third molars. BEWE classifies free surfaces into 4 scores, as follows: 0 , without erosive wear; 1 , initial loss of surface texture; 2 , distinct defect, hard tissue loss $<50 \%$ of the surface area; 3 , distinct defect, hard tissue loss $\geq 50 \%$ of the surface area.

\section{Reproducibility}

Clinical examinations were performed by two examiners. First, the examiners performed a theoretical training exercise by analyzing photographs, and then conducted clinical examinations under the supervision of a benchmark examiner, with experience in this type of ETW examination. The intraexaminer and interexaminer reproducibility was assessed prior to the beginning of the study by double exams in 10 adolescents. The values of the intraexaminer kappa coefficient were 0.90 and 0.93 , and the interexaminer kappa value was 0.77 . Throughout the data collection, the calibration of the examiners was checked by double examinations in 10 students to every 200 students examined, totaling $5 \%$ of the sample. The minimal kappa values were 0.75 (intraexaminer) and 0.75 (interexaminer).

\section{Ethics}

The study protocol was approved by the Research Ethics Committee of the Federal University of Santa Maria (number 2.178.299). The research was conducted ethically in accordance with the World Medical Association Declaration of Helsinki. All patients or their legal guardians signed a written informed consent form. Students received a report of their oral health status, and were referred to dental treatment when needed.

\section{Data analysis}

The outcomes of this study were the prevalence, extent, and severity of ETW. Prevalence was defined as the percentage of individuals presenting at least one tooth with ETW experience. Extent was defined as the number of affected surfaces/teeth. Severity was categorized into no ETW (all teeth with score 0 ), mild ETW ( $\geq 1$ tooth with score 1 ), or severe ETW ( $\geq 1$ tooth with scores 2 or 3 ).

Skin color was dichotomized as a binary variable (non-white or white). Mother's education and father's education were categorized into $\leq$ elementary school, high school, or university. Socioeconomic status (SES) used cutoffs points proposed by the standard Brazilian economic classification, ${ }^{17}$ and households were classified into low $(\leq 16$ points, corresponding to social classes D and E), mid-low ( $\geq 17$ to $\leq 22$ points, corresponding to social class $\mathrm{C} 2$ ), mid-high ( $\geq 23$ to $\leq 28$ points, corresponding to social class $\mathrm{C} 1$ ) or high ( $\geq 29$ points, corresponding to social classes A, B1, and B2). Family income was classified into $\leq 2$ Brazilian minimum wages (BMW) or $>2 \mathrm{BMW}$ (1 BMW corresponded to approximately USD 250 at the time of the data collection). Household crowding was calculated as the number of persons per room, and then categorized as high ( $>2$ persons/room), medium ( $>1$ to $\leq 2$ persons/room), or low ( $\leq 1$ person/room). The presence of tap water and paved streets was collected as 'yes' or 'no' variables.

Data analysis was performed using STATA software (Stata 14.2 for Windows; Stata Corporation, College Station, USA), and using survey commands that took into account the survey design, including clustering, stratification, weighting, and robust variance estimation. A weight variable based on the probability of selection and population distribution according to gender and school type was used to adjust for the potential bias in the population estimates. ${ }^{18}$ Pairwise comparisons for demographic and socioeconomic variables were performed using the Wald test.

The association between explanatory variables and outcomes (ETW prevalence and extent) was assessed using Poisson regression models. The prevalence ratios (PR), rate ratios (RR), and their respective 95\% confidence intervals (CI), were estimated and reported. Explanatory variables presenting $\mathrm{p}<0.25$ in the unadjusted analysis were selected for inclusion in the adjusted analysis; however, only variables significantly associated with the outcome $(p<0.05)$ were maintained in the final model. The chosen level of significance was $5 \%$. 


\section{Results}

Of a total of 1,656 adolescents invited to participate in the study, 1,197 were examined (Figure 1), yielding a participation rate of $72.3 \%$. Among the 459 non-respondents, 369 were public school attendees, and 90 were private school attendees, with an even distribution between boys and girls. The six schools that did not agree to participate in the study were spread evenly throughout city regions.

A total of 675 adolescents presented at least one tooth with ETW, yielding a prevalence rate of $57 \%$ $(95 \% \mathrm{CI}=52.5-61.5)$. Regarding severity, 186 individuals had severe ETW (BEWE scores 2 and 3), corresponding to a prevalence rate of $16 \%(95 \% \mathrm{CI}=13.5-18.6)$, whereas the remaining 489 adolescents had only mild ETW (BEWE score 1). Overall, this adolescent population presented $13.3(95 \% \mathrm{CI}=12.1-14.5)$ affected surfaces, and $8.34(95 \% \mathrm{CI}=7.55-9.13)$ affected teeth. Among the individuals with ETW, 23.3 (95\%CI=20.7-25.9) surfaces, and $14.6(95 \% \mathrm{CI}=13.9-15.4)$ teeth were affected by ETW, on average.

Table 1 presents the frequency distribution of the sample, prevalence, and extent of ETW by explanatory variables. ETW prevalence differed significantly between categories of gender and SES, considering that boys and individuals with higher SES were more commonly affected by ETW. Extent of ETW was significantly different between the categories of gender, skin color, SES, and family income. Boys, white adolescents, and those with higher SES and higher family income showed a greater number of affected surfaces.

The association between explanatory variables and ETW prevalence is shown in Table 2. Gender and SES were significantly associated with this outcome in both the unadjusted and adjusted models. Girls had $11 \%$ lower prevalence of ETW than boys ( $\mathrm{PR}=0.89$, $95 \% \mathrm{CI}=0.81-0.97)$, and individuals with mid-high $(\mathrm{PR}=1.21,95 \% \mathrm{CI}=1.01-1.44)$ and high $(\mathrm{PR}=1.17$, $95 \% \mathrm{CI}=1.01-1.36)$ SES were more likely to have ETW than their counterparts with low SES.

Table 3 shows the association between explanatory variables and extent of ETW. In the unadjusted models, gender, skin color, SES, and family income were associated with the number of affected surfaces. In the adjusted model, girls were found to have $17 \%$ fewer surfaces affected by ETW than boys

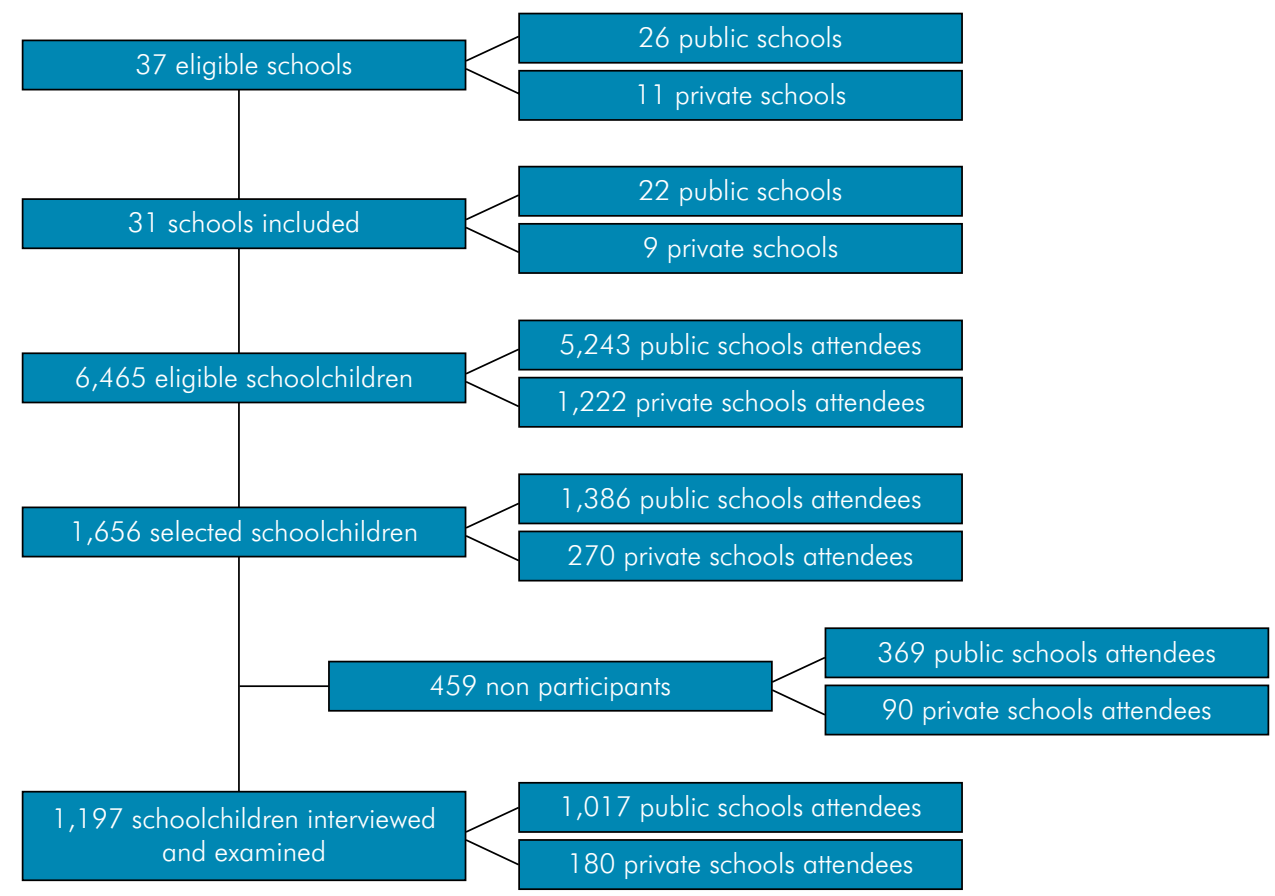

Figure 1. Flowchart of the study. 
Table 1. Sample distribution, prevalence and extent (mean number of affected surfaces) of ETW by explanatory variables. Santa Maria, Brazil, 2018 ( $n=1,197)$.

\begin{tabular}{|c|c|c|c|}
\hline Variable & n (\%) & Prevalence $(95 \% \mathrm{Cl})$ & Extent $(95 \% \mathrm{Cl})$ \\
\hline \multicolumn{4}{|l|}{ Gender } \\
\hline Boys & $513(42.9)$ & $60.7(55.1-66.3)^{a}$ & $14.5(12.9-16.1)^{a}$ \\
\hline Girls & $684(57.1)$ & $53.5(48.7-58.3)^{b}$ & $12.2(10.7-13.6)^{b}$ \\
\hline \multicolumn{4}{|l|}{ Age } \\
\hline 15 & $276(23.0)$ & $55.0(48.1-61.9)^{a}$ & $12.7(10.9-14.6)^{a}$ \\
\hline 16 & $379(31.7)$ & $58.5(52.7-64.2)^{a}$ & $14.1(12.4-15.8)^{a}$ \\
\hline 17 & $367(30.7)$ & $58.3(52.2-64.3)^{a}$ & $13.7(11.9-15.4)^{\mathrm{a}}$ \\
\hline $18-19$ & $175(14.6)$ & $54.4(45.3-63.5)^{a}$ & $11.4(9.0-13.8)^{\circ}$ \\
\hline \multicolumn{4}{|l|}{ Skin color } \\
\hline Non White & $384(33.0)$ & $53.9(46.3-61.6)^{a}$ & $12.0(10.6-13.4)^{a}$ \\
\hline White & $779(67.0)$ & $58.3(54.1-62.5)^{a}$ & $14.1(12.7-15.4)^{b}$ \\
\hline \multicolumn{4}{|l|}{ School } \\
\hline Public & $1,017(85.0)$ & $56.0(51.1-60.9)^{a}$ & $13.1(11.8-14.4)^{\mathrm{a}}$ \\
\hline Private & $180(15.0)$ & $61.6(54.0-69.1)^{a}$ & $14.1(10.6-17.5)^{\mathrm{a}}$ \\
\hline \multicolumn{4}{|l|}{ Mother's education } \\
\hline$\leq$ Primary school & $577(50.2)$ & $56.6(49.6-63.6)^{a}$ & $12.7(11.1-14.2)^{\circ}$ \\
\hline High school & $380(33.1)$ & $56.9(51.5-62.3)^{a}$ & $13.5(11.9-15.0)^{a}$ \\
\hline University & $192(16.7)$ & $59.5(50.9-68.2)^{a}$ & $15.0(12.6-17.4)^{\circ}$ \\
\hline \multicolumn{4}{|l|}{ Father's education } \\
\hline$\leq$ Primary school & $623(56.4)$ & $57.1(51.4-62.8)^{a}$ & $13.1(11.5-14.6)^{\mathrm{a}}$ \\
\hline High school & $356(32.3)$ & $55.5(48.8-62.2)^{a}$ & $13.0(11.3-14.8)^{a}$ \\
\hline University & 125 (1 1.3) & $61.1(50.9-71.3)^{\mathrm{a}}$ & $15.6(12.4-18.9)^{\circ}$ \\
\hline \multicolumn{4}{|l|}{ Socioeconomic status } \\
\hline Low & $201(17.4)$ & $49.2(43.0-55.4)^{a}$ & $10.5(7.5-13.5)^{\circ}$ \\
\hline Mid-low & $320(27.6)$ & $57.1(47.6-66.5)^{a b}$ & $12.8(10.8-14.7)^{\mathrm{ab}}$ \\
\hline Mid-high & $302(26.1)$ & $59.6(51.8-67.4)^{\mathrm{b}}$ & $14.2(12.5-16.0)^{\mathrm{bc}}$ \\
\hline High & 335 (28.9) & $58.1(51.5-64.8)^{\mathrm{b}}$ & $14.3(12.3-16.3)^{\mathrm{bc}}$ \\
\hline \multicolumn{4}{|l|}{ Family income } \\
\hline$\leq 2 \mathrm{BMW}$ & $602(54.2)$ & $54.2(48.8-59.6)^{a}$ & $11.7(10.4-13.0)^{a}$ \\
\hline$>2 \mathrm{BMW}$ & $509(45.8)$ & $60.2(54.7-65.6)^{a}$ & $14.8(13.1-16.5)^{\mathrm{b}}$ \\
\hline \multicolumn{4}{|l|}{ Crowding } \\
\hline High & $124(10.8)$ & $48.8(38.9-58.6)^{a}$ & $11.4(7.8-14.9)^{\circ}$ \\
\hline Medium & $751(65.3)$ & $57.8(53.0-62.6)^{a}$ & $13.4(12.0-14.9)^{\mathrm{a}}$ \\
\hline Low & 275 (23.9) & $59.0(52.0-65.9)^{a}$ & $14.1(12.2-16.0)^{a}$ \\
\hline \multicolumn{4}{|l|}{ Tap water } \\
\hline No & $95(8.1)$ & $62.8(50.1-75.5)^{a}$ & $15.1(10.4-19.9)^{a}$ \\
\hline Yes & $1,074(91.9)$ & $56.7(52.1-61.3)^{a}$ & $13.2(12.1-14.2)^{\mathrm{a}}$ \\
\hline \multicolumn{4}{|l|}{ Paved street } \\
\hline No & $456(39.3)$ & $59.0(53.9-64.0)^{a}$ & $12.7(11.0-14.5)^{\mathrm{a}}$ \\
\hline Yes & $704(60.7)$ & $56.3(50.6-61.9)^{a}$ & $13.8(12.4-15.2)^{a}$ \\
\hline Total & $1,197(100)$ & $57.0(52.5-61.5)$ & $13.3(12.1-14.5)$ \\
\hline
\end{tabular}

Cl: Confidence interval; BMW: Brazilian minimum wage (1 BMW corresponded to approximately USD 250 at the time of the data collection); Different letters indicate a statistically significant difference between categories ( $p<0.05$, adjusted Wald test). 
Erosive tooth wear among South Brazilian adolescents, and its association with sociodemographic variables

Table 2. Association between explanatory variables and ETW prevalence. Unadjusted and adjusted Poisson regression analyses. Santa Maria, Brazil, 2018 ( $n=1,197)$.

\begin{tabular}{|c|c|c|c|c|c|c|}
\hline \multirow{2}{*}{ Variable } & \multicolumn{3}{|c|}{ Unadjusted } & \multicolumn{3}{|c|}{ Adjusted } \\
\hline & PR & $95 \% \mathrm{Cl}$ & $\mathrm{p}$-value & PR & $95 \% \mathrm{Cl}$ & $\mathrm{p}$-value \\
\hline \multicolumn{7}{|l|}{ Gender } \\
\hline Boys & 1.00 & & & 1.00 & & \\
\hline Girls & 0.88 & $0.80-0.96$ & 0.008 & 0.89 & $0.81-0.97$ & 0.01 \\
\hline \multicolumn{7}{|l|}{ Age } \\
\hline 15 & 1.00 & & & & & \\
\hline 16 & 1.06 & $0.94-1.20$ & 0.31 & & & \\
\hline 17 & 1.06 & $0.90-1.24$ & 0.46 & & & \\
\hline 18-19 & 1.00 & $0.84-1.16$ & 0.89 & & & \\
\hline
\end{tabular}

Skin color

\begin{tabular}{|c|c|c|c|}
\hline Non White & 1.00 & & \\
\hline White & 1.08 & $0.95-1.23$ & 0.23 \\
\hline \multicolumn{4}{|l|}{ School } \\
\hline Public & 1.00 & & \\
\hline Private & 1.10 & $0.94-1.28$ & 0.21 \\
\hline \multicolumn{4}{|l|}{ Mother's education } \\
\hline$\leq$ Elementary school & 1.00 & & \\
\hline High school & 1.00 & $0.89-1.14$ & 0.93 \\
\hline University & 1.05 & $0.86-1.28$ & 0.60 \\
\hline \multicolumn{4}{|l|}{ Father's education } \\
\hline$\leq$ Elementary school & 1.00 & & \\
\hline High school & 0.97 & $0.85-1.10$ & 0.65 \\
\hline University & 1.07 & $0.87-1.32$ & 0.51 \\
\hline
\end{tabular}

Socioeconomic status

\begin{tabular}{lcccccc} 
Low & 1.00 & \multicolumn{3}{c}{1.00} & 0.16 \\
Mid-low & 1.16 & $0.95-1.41$ & 0.14 & 1.15 & $0.94-1.42$ & 0.04 \\
Mid-high & 1.21 & $1.02-1.44$ & 0.03 & 1.21 & $1.01-1.44$ & 0.04 \\
High & 1.18 & $1.02-1.37$ & 0.03 & 1.17 & $1.01-1.36$
\end{tabular}

Family income

$\leq 2 \mathrm{BMW}$

1.00

$>2 \mathrm{BMW}$

1.11

$0.99-1.24$

0.06

Crowding

$\begin{array}{llll}\text { High } & 1.00 & & \\ \text { Medium } & 1.18 & 0.95-1.47 & 0.12 \\ \text { Low } & 1.21 & 0.96-1.52 & 0.10\end{array}$

Tap water

\begin{tabular}{|c|c|c|c|}
\hline No & 1.00 & & \\
\hline Yes & 0.90 & $0.73-1.11$ & 32 \\
\hline
\end{tabular}

Paved street

No 1.00

$\begin{array}{llll}\text { Yes } & 0.95 & 0.86-1.06 & 0.37\end{array}$

PR: Prevalence ratio; Cl: Confidence interval; BMW: Brazilian minimum wage (1 BMW corresponded to approximately USD 250 dollars at the time of the data collection). 
Table 3. Association between explanatory variables and extent of ETW (mean number of affected surfaces). Unadjusted and adjusted Poisson regression analyses. Santa Maria, Brazil, 2018 ( $n=1,197)$.

\begin{tabular}{|c|c|c|c|c|c|c|}
\hline \multirow{2}{*}{ Variable } & \multicolumn{3}{|c|}{ Unadjusted } & \multicolumn{3}{|c|}{ Adjusted } \\
\hline & RR & $95 \% \mathrm{Cl}$ & $p$-value & RR & $95 \% \mathrm{Cl}$ & $\mathrm{p}$-value \\
\hline \multicolumn{7}{|l|}{ Gender } \\
\hline Boys & 1.00 & & & 1.00 & & \\
\hline Girls & 0.84 & $0.73-0.96$ & 0.02 & 0.83 & $0.73-0.96$ & 0.01 \\
\hline \multicolumn{7}{|l|}{ Age } \\
\hline 15 & 1.00 & & & & & \\
\hline 16 & 1.11 & $0.97-1.26$ & 0.12 & & & \\
\hline 17 & 1.07 & $0.89-1.30$ & 0.44 & & & \\
\hline 18-19 & 0.90 & $0.70-1.14$ & 0.36 & & & \\
\hline \multicolumn{7}{|l|}{ Skin color } \\
\hline Non White & 1.00 & & & 1.00 & & \\
\hline White & 1.17 & $1.04-1.31$ & 0.01 & 1.12 & $1.01-1.25$ & 0.03 \\
\hline \multicolumn{7}{|l|}{ School } \\
\hline Public & 1.00 & & & & & \\
\hline Private & 1.07 & $0.82-1.40$ & 0.60 & & & \\
\hline \multicolumn{7}{|l|}{ Mother's education } \\
\hline$\leq$ Primary school & 1.00 & & & & & \\
\hline High school & 1.06 & $0.92-1.22$ & 0.37 & & & \\
\hline University & 1.18 & $0.98-1.43$ & 0.08 & & & \\
\hline \multicolumn{7}{|l|}{ Father's education } \\
\hline$\leq$ Primary school & 1.00 & & & & & \\
\hline High school & 1.00 & $0.85-1.17$ & 0.98 & & & \\
\hline University & 1.20 & $0.96-1.49$ & 0.10 & & & \\
\hline \multicolumn{7}{|l|}{ Socioeconomic status } \\
\hline Low & 1.00 & & & 1.00 & & \\
\hline Mid-low & 1.22 & $0.86-1.71$ & 0.25 & 1.23 & $0.87-1.75$ & 0.23 \\
\hline Mid-high & 1.36 & $1.02-1.80$ & 0.03 & 1.34 & $1.00-1.79$ & 0.05 \\
\hline High & 1.36 & $1.03-1.80$ & 0.03 & 1.34 & $1.01-1.77$ & 0.04 \\
\hline \multicolumn{7}{|l|}{ Family income } \\
\hline$\leq 2 \mathrm{BMW}$ & 1.00 & & & & & \\
\hline$>2 \mathrm{BMW}$ & 1.26 & $1.10-1.46$ & 0.002 & & & \\
\hline \multicolumn{7}{|l|}{ Crowding } \\
\hline High & 1.00 & & & & & \\
\hline Medium & 1.18 & $0.87-1.59$ & 0.27 & & & \\
\hline Low & 1.23 & $0.86-1.77$ & 0.24 & & & \\
\hline \multicolumn{7}{|l|}{ Tap water } \\
\hline No & 1.00 & & & & & \\
\hline Yes & 0.87 & $0.66-1.15$ & 0.32 & & & \\
\hline \multicolumn{7}{|l|}{ Paved street } \\
\hline No & 1.00 & & & & & \\
\hline Yes & 1.08 & $0.93-1.26$ & 0.29 & & & \\
\hline
\end{tabular}

RR: Rate ratio; Cl: Confidence interval; BMW: Brazilian minimum wage (1 BMW corresponded to approximately USD 250 dollars at the time of the data collection). 
$(\mathrm{RR}=0.83,95 \% \mathrm{CI}=0.73-0.96) ;$ white adolescents had $12 \%$ more affected surfaces than non-white individuals $(\mathrm{RR}=1.12,95 \% \mathrm{CI}=1.01-1.25)$; and individuals with mid-high and high SES had 34\% more affected surfaces than individuals with low SES (mid-high, $\mathrm{RR}=1.34,95 \% \mathrm{CI}=1.00-1.79$; high, $\mathrm{RR}=1.34,95 \% \mathrm{CI}=1.01-1.77)$. A strong correlation was observed between SES and family income; thus, it was decided that only SES should be retained in the final model, since it is a broader variable and had fewer missing data.

The prevalence of ETW according to tooth and gender is shown in Figure 2. The most commonly affected teeth were the upper incisors; however, lower first molars were the teeth most affected by severe ETW. The greater occurrence of ETW among boys is easily detectable in Figure 2.

\section{Discussion}

This cross-sectional population-based study was conducted to investigate the occurrence of ETW among 15-19-year-old adolescents from southern Brazil. We found a high prevalence of ETW, which was mild in most cases. ETW was significantly

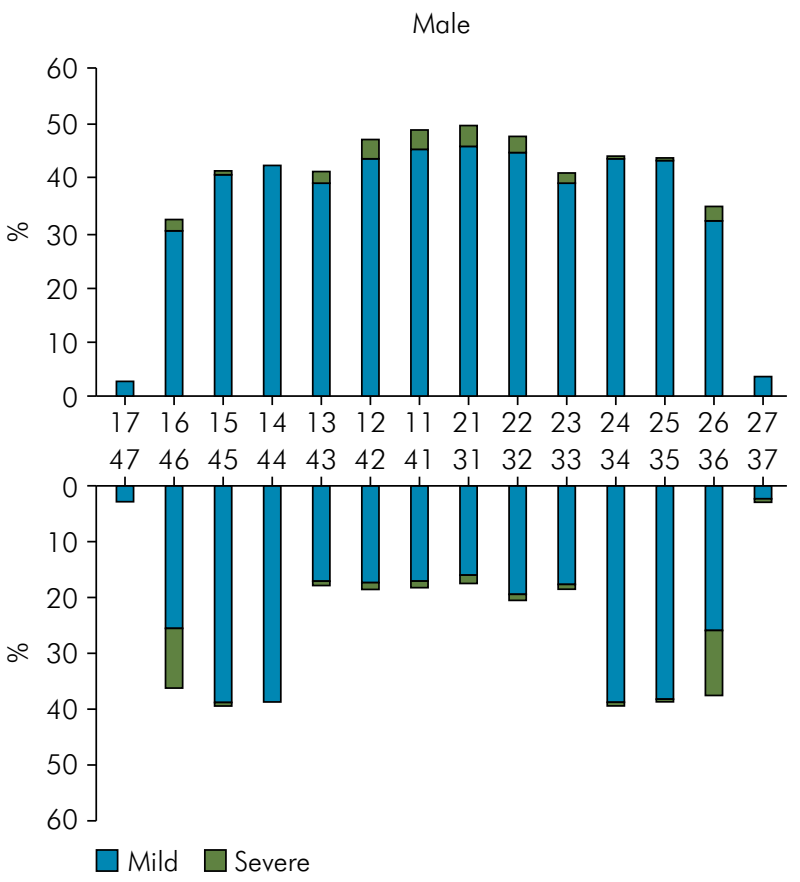

associated with gender, skin color, and SES in this adolescent population.

In the present study, the ETW prevalence of 57\% was similar to previous studies conducted in Poland $(59.8 \%),{ }^{3}$ Colombia (57.3\%), ${ }^{5}$ and Norway $(59 \%),{ }^{9}$ but higher than most studies involving adolescents and young adults. . $, 6,7,8,10$ The differences among the studies could be attributed to the different methods/criteria of examination, sample size, age group, and setting. In Brazil, the previous published study including 15-19-year-old individuals found an ETW prevalence rate of $21 \%{ }^{10}$ This lower prevalence could be explained by the partial recording protocol used (only upper incisors and first molars were clinically assessed), in contrast to our study, which included all erupted teeth, except third molars. In addition, the sensitivity of our clinical examination may have increased due to the supine position, use of artificial light, tooth cleaning and drying. A previous study conducted in Santa Maria, involving 11-14-year-old schoolchildren, found an ETW prevalence of $7.2 \% .{ }^{19}$ We can presume that the longer time at risk to ETW, related to the older age of our sample, may have played a role in causing the higher occurrence found in our study, not to mention the effect of different clinical examination

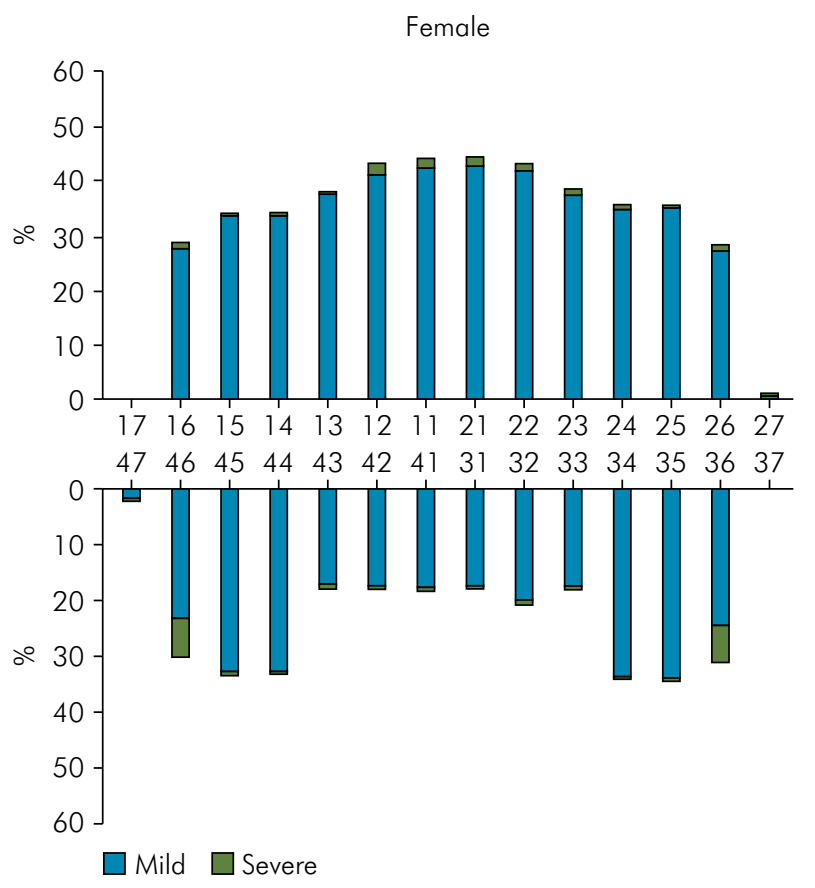

Figure 2. Prevalence of erosive tooth wear according to tooth and gender. 
protocols (use of natural light and gauze to clean and dry tooth surfaces in that study).

The socioeconomic conditions in which individuals find themselves may be responsible for the greater susceptibility of some individuals to develop diseases than others. The negative influence of a poor socioeconomic background on oral health outcomes, such as dental caries ${ }^{20}$ and gingival bleeding, ${ }^{21}$ has been demonstrated previously. Nevertheless, the influence of socioeconomic factors on ETW has not yet been well established. In a literature review of studies conducted in Brazil, only 2 out of 8 studies found a significant relationship between SES and ETW, with a higher prevalence among individuals with a higher socioeconomic level. ${ }^{22}$ This association was not found in the only Brazilian study that involved 15-19-year-old adolescents. ${ }^{10}$ Regarding income, another Brazilian study involving 335 individuals aged 12 to 30 years found a relationship between ETW and middle family income (1-3 BMW) in a preliminary analysis; however, no significant association was observed in the risk assessment analysis. ${ }^{4}$ In the present study, we found an association between mid-high and high SES and ETW in the unadjusted and adjusted analyses for both outcomes (prevalence and extent). In addition, family income was also associated with a greater number of affected surfaces in the unadjusted analysis for extent of ETW. Considering the well-known relationship between dietary acids and ETW, 1,2,4,5,26,34,36 no dietary information was included in the present study, since we intended to assess the specific association between distal sociodemographic factors and ETW, without the interference of proximal factors such as diet. Notwithstanding, despite the lack of mediation analysis in the present study, we can assume that the mechanisms by which sociodemographic factors influence the occurrence of ETW are related to dietary patterns and lifestyle. Individuals of more affluent status are more likely to have healthier habits, including higher fruit/vegetable consumption ${ }^{23,24}$ and higher tooth brushing frequency (which may have a synergistic effect on ETW). ${ }^{25}$ According to Carvalho, ${ }^{11}$ economic capital allows greater access to care and better living conditions, which make it easier to cope with the health-disease process; however, this capital can also generate specific risks. This seems to be the case of ETW among Brazilian adolescents.

Regarding the demographic variables, our study found significant associations with gender and skin color. Boys were more likely to have ETW in both the prevalence and extent analyses, corroborating previous studies. ${ }^{26,27,28,29}$ This greater likelihood among boys can be explained by behavioral and lifestyle factors, such as greater practice of vigorous-intensity physical activities, ${ }^{30}$ which affects salivary quantity and quality; higher consumption of acid foods ${ }^{31}$ and fizzy drinks, ${ }^{32}$ and greater bite force. ${ }^{33}$ Few studies have investigated the relationship between skin color and ETW. The Brazilian study involving 15-19-year-olds found no significant difference in relation to the selfreported ethnicity of the participants and ETW.$^{10} \mathrm{On}$ the other hand, a study published in 2011 reported that black individuals had less ETW than white ones. ${ }^{34}$ Similarly, a longitudinal study evaluating the progression of ETW in a sample of 1,753 12-year-old schoolchildren showed a significant association between ETW and white children. ${ }^{35}$ In our study, we also found that white adolescents had more affected surfaces than non-white individuals. Although skin color could be considered a socioeconomic indicator in the present study, we must acknowledge that it remained significantly associated with ETW even after the adjustment for SES. The mechanism by which skin color is associated with ETW irrespective of SES is unclear. Curiously, no relationship was found between age and ETW in our study.

The upper incisors were the teeth most commonly affected by ETW, and the lower first molars were the teeth most heavily affected by severe ETW, mainly among boys. This is a conceivable finding since incisors and first molars were at risk for ETW for a longer period of time, because of their early eruption, compared with canines and premolars, as corroborated by a previous study by Bartlett et al. ${ }^{36}$ Cuppings in the molar cusps are the clinical signs most commonly observed in adolescents. ${ }^{37}$ One factor that may contribute to greater ETW severity in the occlusal surfaces among boys is that they may have greater maximal voluntary contraction of masseter and anterior temporal muscles than girls, resulting in greater bite force. ${ }^{33}$ In addition, the intraoral 
distribution of ETW may vary depending on the origin of the acid (intrinsic or extrinsic). ${ }^{36}$

Among the strengths of our study, we could emphasize its external validity, since all public and private high schools in the municipality were invited to participate, including all school periods (morning, afternoon, and night). Although six schools did not agree to participate, they were distributed proportionally according to school type and spread evenly throughout city regions. Accordingly, we may consider our sample as representative of the population. In addition, two examiners performed reproducibility control during data collection, a factor that may reinforce the internal validity of the study. We could also emphasize the examination protocol of our study, including supine position, artificial light, and tooth cleaning and drying. Nevertheless, the high sensitivity of the clinical examination may have overestimated the study results. A possible limitation of our study could be the lower participation rate in private schools $(66.7 \%)$ than in public schools (73.4\%). A weight variable was used in all the analyses to adjust for this potential bias, as previously described.

\section{Conclusion}

This population-based cross-sectional study showed a high prevalence of ETW among 15-19-year-old South Brazilian adolescents, which was mild ETW in most cases. Sociodemographic variables were significantly associated with ETW. Boys, white adolescents, and those pertaining to mid-high and high SES were more affected and should be targeted for preventive strategies against ETW.

\section{Acknowledgements}

We acknowledge the support provided by the Federal University of Santa Maria, the Municipal Oral Health Policy of Santa Maria, and the National Coordination of Post-graduate Education (CAPES), Ministry of Education, Brazil. We also thank all the adolescents, parents/legal guardians and schools who took part in this study.

\section{References}

1. Lussi A. (Ed.). Dental erosion: from diagnosis to therapy. Basel. Karger; 2006. (Monographs in oral Science, Vol. 20).

2. Kanzow P, Wegehaupt FJ, Attin T, Wiegand A. Etiology and pathogenesis of dental erosion. Quintessence Int. 2016 Apr;47(4):275-8. https://doi.org/10.3290/i.qi.a35625

3. Bachanek T, Hendzel B, Wolańska E, Szybinsky V, Ogonovsky R, Hrynovets V, et al. Prevalence of dental erosion among 18-year-old adolescents in the borderland districts of Lviv (Ukraine) and Lublin (Poland). Ann Agric Environ Med. 2018 Mar;25(1):66-70. https://doi.org/10.5604/12321966.1228948

4. Luciano L, Ferreira MC, Paschoal MA. Prevalence and factors associated with dental erosion in individuals aged $12-30$ years in a northeastern Brazilian city. Clin Cosmet Investig Dent. 2017 Out; 9(1): 85-91. https://doi.org/10.2147/CCIDE.S144150

5. Mafla AC, Cerón-Bastidas XA, Munoz-Ceballos ME, Vallejo-Bravo DC, Fajardo-Santacruz MC. Prevalence and extrinsic risk factors for dental erosion in adolescents. J Clin Pediatr Dent. 2017;41(2):102-11. https://doi.org/10.17796/1053-4628-41.2.102

6. Strużycka I, Rusyan E, Bogusławska-Kapała A. [Epidemiological study of prevalence and risk factors for dental erosions among Polish young adults]. Pol Merkur Lekarski. 2016 May;40(239):308-13. Polish.

7. Kirthiga M, Poornima P, Praveen R, Sakeena B, Disha P. Dental erosion and its associated factors in 11-16-year old school children. J Clin Pediatr Dent. 2015;39(4):336-42. https://doi.org/10.17796/1053-4628-39.4.336

8. Kitasako Y, Sasaki Y, Takagaki T, Sadr A, Tagami J. Age-specific prevalence of erosive tooth wear by acidic diet and gastroesophageal reflux in Japan. J Dent. 2015 Apr;43(4):418-23. https://doi.org/10.1016/i.jdent.2015.02.004

9. Sovik JB, Tveit AB, Storesund T, Mulic A. Dental erosion: a widespread condition nowadays? A cross-sectional study among a group of adolescents in Norway. Acta Odontol Scand. 2014 Oct; 72(7): 523-29. https://doi.org/10.3109/00016357.2013.875588

10. Aguiar YP, Santos FG, Moura EF, Costa FC, Auad SM, Paiva SM, et al. Association between dental erosion and diet in Brazilian adolescents aged from 15 to 19: a population-based study. ScientificWorldJournal. 2014 Feb;2014(1):818167. https://doi.org/10.1155/2014/818167

11. Carvalho Al. Determinantes sociais, econômicos e ambientais da saúde: a saúde no Brasil em 2030: prospecção estratégica do sistema de saúde brasileiro: população e perfil sanitário. Rio de Janeiro: Fiocruz; 2013.2 v. 
12. Silva JV, Machado FC, Ferreira MA. As desigualdades sociais e a saúde bucal nas capitais brasileiras. Cien Saude Colet. 2015 Ago;20(8):2539-48. https://doi.org/10.1590/1413-81232015208.12052014

13. Magalhães AC, Wiegand A, Rios D, Honório HM, Buzalaf MA. Insights into preventive measures for dental erosion. J Appl Oral Sci. 2009 Mar-Apr;17(2):75-86. https://doi.org/10.1590/S1678-77572009000200002

14. Zero DT, Lussi A. Behavioral factors. In: Lussi A. (Ed.). Dental erosion: from diagnosis to therapy. Basel. Karger; 2006. (Monographs in oral Science, Vol. 20). p. 100-5.

15. Piovesan C, Mendes FM, Antunes JL, Ardenghi TM. Inequalities in the distribution of dental caries among 12-year-old Brazilian schoolchildren. Braz Oral Res. 2011 Jan-Feb;25(1):69-75. https://doi.org/10.1590/S1806-83242011000100012

16. Bartlett D, Ganss C, Lussi A. Basic Erosive Wear Examination (BEWE): a new scoring system for scientific and clinical needs. Clin Oral Investig. 2008 Mar;12(1 Suppl 1):S65-8. https://doi.org/10.1007/s00784-007-0181-5

17. Associação Brasileira de Estudos Populacionais - ABEP. Critério de classificação econômica brasileira. São Paulo: Associação Brasileira de Estudos Populacionais; 2015.

18. Korn B, Graubard E. Analysis of health surveys. New York: John Wiley \& Sons; 1999.

19. Vargas FF, Pratzel JR, Ardenghi TM. Prevalence of tooth erosion and associated factors in 11-14-year-old Brazilian schoolchildren. J Public Health Dent. 2010 Ago; $71(1): 6-12$.

20. Engelmann JL, Tomazoni F, Oliveira MD, Ardenghi TM. Association between dental caries and socioeconomic factors in schoolchildren: a multilevel analysis. Braz Dent J. 2016 Jan-Feb;27(1):72-8. https://doi.org/10.1590/0103-6440201600435

21. Sfreddo CS, Moreira CH, Celeste RK, Nicolau B, Ardenghi TM. Pathways of socioeconomic inequalities in gingival bleeding among adolescents. Community Dent Oral Epidemiol. 2019 Apr;47(2):177-84. https://doi.org/10.1111/cdoe.12441

22. Farias MM, Silveira EG, Schmitt BH, Araújo SM, Baier IB. Prevalência da erosão dental em crianças e adolescentes brasileiros. Rev Salusvita. 2013;32(2):187-98.

23. Darmon N, Drewnowski A. Does social class predict diet quality? Am J Clin Nutr. 2008 May;87(5):1107-17. https://doi.org/10.1093/ajcn/87.5.1107

24. Mayén AL, Marques-Vidal P, Paccaud F, Bovet P, Stringhini S. Socioeconomic determinants of dietary patterns in low-and middle-income countries: a systematic review. Am J Clin Nutr. 2014 Dec;100(6):1520-31. https://doi.org/10.3945/ajcn.114.089029

25. Freire MC, Sheiham A, Bino YA. Hábitos de higiene bucal e fatores sociodemográficos em adolescentes. Rev Bras Epidemiol. 2007 Dez;10(4):606-14. https://doi.org/10.1590/S1415-790X2007000400018

26. Alves LS, Brusius CD, Damé-Teixeira N, Maltz M, Susin C. Dental erosion among 12-year-old schoolchildren: a population-based cross-sectional study in South Brazil. Int Dent J. 2015 Out;65(6):322-30. https://doi.og/10.1111/idj.12189

27. Mangueira DF, Sampaio FC, Oliveira AF. Association between socioeconomic factors and dental erosion in Brazilian schoolchildren. J Public Health Dent. 2009;69(4):254-9. https://doi.org/10.1111/j.1752-7325.2009.00131.x

28. Dugmore CR, Rock WP. The prevalence of tooth erosion in 12-year-old children. Br Dent J. 2004 Mar;196(5):279-82. https://doi.org/10.1038/sj.bdj.4811040

29. Milosevic A, Young PJ, Lennon MA. The prevalence of tooth wear in 14 -year-old school children in Liverpool. Community Dent Health. 1994 Jun;11(2):83-6.

30. Azevedo MR, Araúio CL, Reichert FF, Siqueira FV, Silva MC, Hallal PC. Gender differences in leisure-time physical activity. Int J Public Health. 2007;52(1):8-15. https://doi.org/10.1007/s00038-006-5062-1

31. Gambon DL, Brand HS, Veerman EC. Dental erosion in the 21 st century: what is happening to nutritional habits and lifestyle in our society? Br Dent J 2012. Jul; 213(2): 55-7. https://doi.org/10.1038/si.bdj.2012.613

32. Scully M, Morley B, Niven P, Crawford D, Pratt IS, Wakefield M. Factors associated with high consumption of soft drinks among Australian secondary-school students. Public Health Nutr. 2017 Sep;20(13):2340-8. https://doi.org/10.1017/S1368980017000118

33. Kumar M, Verma R, Bansal M, Singh S, Rehan S, Kumar V, et al. To evaluate the severity, distribution of occlusal tooth wear and its correlation with bite force in young North Indian adults. Open Dent J. 2018 Sep;12(12):735-41. https://doi.org/10.2174/1745017901814010735

34. Okunseri C, Okunseri E, Gonzalez C, Visotcky A, Szabo A. Erosive tooth wear and consumption of beverages among children in the United States. Caries Res. 2011;45(2):130-5. https://doi.org/10.1159/000324109

35. Dugmore CR, Rock WP. The progression of tooth erosion in a cohort of adolescents of mixed ethnicity. Int J Paediatr Dent. 2003 Sep;13(5):295-303. https://doi.org/10.1046/j.1365-263X.2003.00487.x

36. Bartlett DW, Fares J, Shirodaria S, Chiu K, Ahmad N, Sherriff M. The association of tooth wear, diet and dietary habits in adults aged $18-30$ years old. J Dent. 2011 Dec;39(12):811-6. https://doi.org/10.1016/i.ident.2011.08.014

37. Holbrook WP, Ganss C. Is diagnosing exposed dentine a suitable tool for grading erosive loss? Clin Oral Investig. 2008 Mar;12(1 Suppl 1):S33-9. https://doi.org/10.1007/s00784-007-0174-4 